\title{
EVOLUÇÃO DOS PREÇOS HISTÓRICOS DA BOVINOCULTURA DE CORTE DO RIO GRANDE DO SUL: TENDÊNCIA E COMPORTAMENTO DOS PREÇOS EM NÍVEL DE PRODUTOR E CONSUMIDOR
}

\author{
Evolution of historic prices of beef cattle production in Rio Grande do Sul: tendency and \\ behavior of prices to farmers and consumers
}

\author{
João Garibaldi Almeida Viana ${ }^{1}$, Renato Santos de Souza ${ }^{2}$, Vicente Celestino Pires Silveira ${ }^{3}$
}

\begin{abstract}
RESUMO
Objetivou-se analisar o comportamento histórico dos preços pagos ao produtor de bovinos de corte e os preços pagos pelos consumidores por diferentes cortes de carne bovina no Rio Grande do Sul, nas últimas décadas. O estudo foi realizado com base em duas séries históricas de preços nominais mensais, a de preços pagos ao produtor, obtida junto à EMATER/RS e a de preços pagos pelo consumidor final, por meio dos valores pagos na comercialização dos cortes alcatra, coxão de dentro, coxão de fora, patinho, chuleta, filé mignon, costela e paleta, obtidos junto ao IEPE/UFRGS. Os preços nominais foram deflacionados para dezembro de 2006 pelo IGP-DI/FGV. Calcularam-se também os Índices de Preço ao consumidor e ao produtor. Para a análise de tendência dos preços reais pagos ao produtor, foram ajustadas retas de regressão sobre os preços reais para os períodos de 1977-1994 e 1995-2006, utilizando-se o método dos mínimos quadrados. Os preços pagos por quilograma de peso vivo do boi gordo no Rio Grande do Sul apresentaram tendência declinante significativa de 1977 a 1994, obtendo maior estabilidade de 1995 a 2006, sem tendência significativa de queda no período. Os preços pagos pelo consumidor não apresentaram o mesmo comportamento de queda dos preços pagos ao produtor, obtendo menor desvalorização no período analisado. Dentre os cortes analisados, os preços da costela e do filé mignon apresentaram comportamento distinto dos demais, verificando-se elevação de preços principalmente durante a década de 1990.
\end{abstract}

Termos para indexação: Bovinocultura de corte, preços agrícolas, séries temporais.

\begin{abstract}
This work analyzes the historical behaviour of prices paid to beef cattle producers and prices paid by consumers for different beef cuts in the state of Rio Grande do Sul in the last decades. This study was based on two historical series of nominal monthly prices: prices paid to the producer, obtained from EMATER/RS and prices paid by the consumer, through commercialization prices of heart of hump, flat, topside, knuckle, ribs, tenderloin, blade, and striploin, obtained from IEPE/UFRGS. The nominal prices were deflationed for December 2006 according to the IGP-DI from the Getúlio Vargas Foundation. The Price Indexes to the consumer and producer were also calculated. For the tendency analysis of real prices paid to the producer, linear regression lines were adjusted over real prices for the periods between 1977-1994 and 1995-2006, using the minimum square method. Prices paid per kilogram of liveweight steers in Rio Grande do Sul presented significant decrease tendency from 1977 to 1994 . However, prices obtained higher stability from 1995 to 2006, with no significant decrease during this period. The prices paid by the consumer did not present the same decreasing behaviour as the prices paid to the producer, resulting in a lower price loss during the analyzed period. Among the analyzed cuts, rib and tenderloin cuts presented different behaviour, with an elevation of prices being verified mainly during the decade of 1990 .
\end{abstract}

Index terms: Beef cattle production, agricultural prices, temporal series.

(Recebido em 5 de novembro de 2007 e aprovado em 8 de maio de 2008)

\section{INTRODUÇÃO}

O agronegócio é visto como a cadeia produtiva que envolve desde a fabricação de insumos, passando pela produção nos estabelecimentos agropecuários e pela sua transformação, até o seu consumo (Gasques et al., 2004). No caso da bovinocultura de corte, existem basicamente quatro elos de processamento nesta cadeia: insumos, agropecuária (produtores), indústria (frigoríficos), distribuição/varejo. Portanto, a cadeia é formada pelo setor à montante da produção (indústrias produtoras de insumos tecnológicos e creditícios), o produtor rural e o setor à jusante da produção (indústrias frigoríficas, curtumes, atacadistas, varejistas e consumidores finais). O produtor

\footnotetext{
Zootecnista, Mestre em Extensão Rural - Universidade Federal de Santa Maria (UFSM), Doutorando em Agronegócios - Universidade Federal do Rio Grande do Sul (UFRGS). Rua Pinheiro Machado, 2694, apt 801, CEP: 97050-600, Centro, Santa Maria - RS. E-mail: joaogaribaldi@brturbo.com.br 2Dr. Prof. Adjunto do Departamento de Educação Agrícola e Extensão Rural/DEAER - Universidade Federal de Santa Maria/UFSM, Santa Maria - RS Brasil. , Faixa de Camobi km 09, Prédio 44, CEP 97105-900, Santa Maria - RS E-mail: rssouza@smail.ufsm.br ${ }^{3}$ Dr. Prof. Adjunto - DEAER /UFSM, Santa Maria - RS - Brasil., Faixa de Camobi km 09, Prédio 44, CEP 97105-900, Santa Maria - RS E-mail: vicentesilveira@smail.ufsm.br
} 
permanece entre setores de mercado altamente especializados e não possui capacidade de formular os preços finais de seu produto (Montoya \& Parré, 2000).

Os preços do quilograma de boi vivo nos últimos anos se mantiveram constantes e os preços dos insumos apresentaram elevação. Esse cenário trouxe um panorama de queda na renda dos pecuaristas, levando muitos fazendeiros a vender parte de suas terras ou deixar o ramo pecuário.

Em dois pontos desta cadeia os preços do produto são públicos: o preço de venda dos animais pelo produtor e o de compra da carne pelos consumidores. A estrutura de comercialização da carne é basicamente dividida em 3 tipos de estabelecimentos: supermercados/hipermercados, açougues e boutiques de carnes (Tellechea, 2001).

Como a cadeia é desarticulada e os supermercados são os responsáveis pela distribuição da grande maioria do produto ao consumidor (Tellechea, 2001), de uma forma geral, são eles que estabelecem as regras na cadeia da carne bovina, principalmente definindo os preços praticados a nível de indústria e produtores rurais. Esta afirmativa está baseada no fato de que o consumidor é o regulador de preços. A elevação do preço do produto ao consumidor final imediatamente reflete na redução ou, até mesmo, na estagnação das vendas. O consumidor é sensível ao aumento de preços, e como ele mantém uma relação muito próxima dos supermercados, repassam os efeitos da "ponta" para os demais elos da cadeia produtiva (Rio Grande do Sul, 2003).

Para produzir o animal para abate o produtor tem um custo de produção que, no momento da venda, precisa ser "repassado" para a indústria. Por sua vez, a indústria é responsável pela transformação em produto carne, que será distribuído ao estabelecimento varejista. Durante este processo há custos para que o produto vivo (boi/vaca) se transforme em alimento para o consumidor (cortes de carne bovina).

Portanto, torna-se imprescindível a análise do comportamento dos preços da carne bovina, nas últimas décadas, em nível de produtor e consumidor, a fim de fornecer subsídios para estudos sobre a cadeia produtiva da bovinocultura, além de disponibilizar dados que contribuam para futuras pesquisas.

Neste trabalho, objetivou-se analisar o comportamento histórico dos preços pagos ao produtor de bovinos de corte e dos preços pagos pelo consumidor de diferentes cortes de carne bovina no Rio Grande do Sul, de 1977 a 2006, dando atenção à tendência dos preços pagos ao produtor durante 1977 a 1994 e, principalmente, após a estabilização monetária obtida com o Plano Real.

\section{METODOLOGIA}

O presente trabalho foi realizado com base em duas séries históricas de preços nominais da bovinocultura de corte do Rio Grande do Sul, de duas fontes diferentes: a) a série de preços médios pagos por quilograma de peso vivo do boi gordo, coletados pela Empresa de Assistência Técnica e Extensão Rural/RS (2007); e b) a série de preços médios pagos pelo consumidor final por diferentes cortes de carne bovina em nível de varejo, coletados pelo Centro de Estudos e Pesquisas Econômicas-IEPE (2007) da Universidade Federal do Rio Grande do Sul. As séries históricas de preços pagos pelo consumidor, coletadas no varejo, compreendem os preços dos cortes: alcatra, coxão de dentro, coxão de fora, patinho, chuleta, filé mignon, paleta e costela. Os dados de preços pagos ao produtor e de preços pagos pelo consumidor abrangem o período de janeiro de 1977 a dezembro de 2006.

O itinerário metodológico partiu de onde partem todos os estudos históricos baseados em preços nominais: da atualização monetária dos mesmos. Assim, após fazer as correções monetárias necessárias relativas aos diferentes planos econômicos, Plano Cruzado, 1986; Plano Verão, 1989; Plano Collor, 1990 e Plano Real, 1994; nos preços nominais históricos, deflacionaram-se os preços corrigidos de cada mês de forma a atualizá-los para valores reais equivalentes a dezembro de 2006, utilizando-se a fórmula (1). Para o deflacionamento dos preços nominais foi utilizado o Índice Geral de Preços, Fundação Getúlio Vargas (2007), calculado pela Fundação Getúlio Vargas, por ser este um índice que reflete tanto preços ao consumidor final como preços no interior das cadeias produtivas e canais de comercialização, classificados como preços no atacado.

$$
\text { PRt }=(\mathrm{PNt} . \mathrm{IPa}) / \mathrm{IPt}
$$

Onde: $\mathrm{PRt}=$ Preço Real no mês " $\mathrm{t}$ ”; $\mathrm{PNn}=$ Preço Nominal corrigido no mês " $t$ "; IPa = IGP-DI de dezembro de 2006; $\mathrm{IPt}=\mathrm{IGP}-\mathrm{DI}$ no mês " $\mathrm{t}$ ".

Com o objetivo de analisar a evolução dos preços pagos ao produtor ao longo das últimas décadas, buscouse verificar a existência de tendência de preços para esta série histórica. Em análise de séries temporais, o termo tendência descreve um movimento suave, a longo prazo, dos dados, para cima ou para baixo, de forma que a análise de tendência diz respeito à verificação da direção do movimento de longo prazo na série temporal (Kazmier, 1982).

Várias são as formas de se avaliar a existência ou não de tendência em uma série temporal de dados, dentre elas estão o uso da taxa geométrica de crescimento (Finamore \& Gomes, 1999) e do coeficiente angular da reta de regressão dos dados (Kazmier, 1982). Em razão da 
simplicidade de interpretação e da eficiência do segundo método em relação ao objetivo proposto, optou-se por ele. Assim, para a análise de tendência dos preços reais pagos ao produtor, foram ajustadas retas de regressão sobre os preços reais para os períodos de 1977-1994, 1995-2006, utilizando-se o método dos mínimos quadrados, conforme Johnston (1977). Tal regressão, com a qual se estimou a equação (2) abaixo, teve, como variável dependente, o preço real médio anual desestacionalizado e como variável independente o período de tempo (em anos).

$$
\mathrm{PT}=\mathrm{a}+\mathrm{b} . \mathrm{T}
$$

Onde: $\mathrm{PT}=$ Preço de tendência; $\mathrm{a}=$ coeficiente linear da reta de tendência; $b=$ coeficiente angular da reta de tendência; $\mathrm{T}=$ Período de tempo $(1,2,3,4,5 \ldots \mathrm{n})$

A existência ou não de tendência declinante ou ascendente nos preços reais pagos ao produtor no período analisado foi verificada por meio do teste de hipóteses tstudent, com o qual se avaliou, a um nível de $95 \%$ de significância, se o coeficiente angular " $b$ " da reta de regressão ajustada aos dados era significativamente diferente de zero. Quando o "t calculado" é maior que o " $t$ tabelado" o coeficiente angular "b" é significativamente diferente de zero (e viceversa), o que caracteriza a existência de tendência, ascendente se "b" for positivo ou declinante se for negativo.

Após analisar a tendência dos preços ao produtor, tornou-se necessário comparar o comportamento desses dados com as séries históricas de preços pagos pelo consumidor. Tanto para a série de preços ao produtor como para as séries de preços dos cortes em nível de varejo foram calculados um Índice de Preço com os dados reais médios anuais, com base 100 em 1977. O Índice de Preço, na medida que transforma valores absolutos (em unidades monetárias) em valores relativos (sem unidade alguma) fixados em uma mesma base, permite que se possa comparar a evolução das diferentes séries históricas de preços.

Além de comparar a série de dados ao produtor com os diferentes cortes coletados em nível de varejo por meio de Índices de Preços, buscou-se determinar uma série histórica que representasse da melhor forma possível o preço médio da carne bovina no varejo. Para este cálculo, utilizouse a percentagem de cada corte na carcaça total para estimar, pelos preços dos cortes coletados, o preço médio da carcaça bovina. Cabe ressaltar que esta análise busca apenas obter um índice de preço médio estimado da carne bovina no varejo, para, desta forma, ter a possibilidade de comparar a evolução dos preços ao produtor e ao consumidor.

Dentre os cortes disponíveis, o corte "paleta" representou o dianteiro na carcaça, o corte "costela" representou o costilhar na carcaça, e os cortes "alcatra", "coxão de fora", "coxão de dentro", "patinho", "chuleta" e "filé mignon" representaram o traseiro na carcaça.

A partir do trabalho de Viana \& Silveira (2007), obtiveram-se as participações de cada parte da carcaça (dianteiro, costilhar e traseiro) na carcaça total (Tabela 1). Dessa forma, ponderaram-se os preços dos diferentes cortes com base na sua participação na carcaça total. Como

Tabela 1 - Participação percentual dos diferentes cortes na carcaça bovina comercializados nos supermercados de Santa Maria. DEAER/NEPEA - UFSM, Santa Maria-RS, 2007.

\begin{tabular}{|c|c|c|c|c|c|}
\hline \multicolumn{2}{|c|}{ Dianteiro } & \multicolumn{2}{|c|}{ Costilhar } & \multicolumn{2}{|c|}{ Traseiro } \\
\hline Corte & Percentual & Corte & Percentual & Corte & Percentual \\
\hline Agulha & 11,19 & Costela & 5,99 & Alcatre & 2,48 \\
\hline Peito & 7,34 & $\begin{array}{c}\text { Costela } \\
\text { desossada }\end{array}$ & 3,16 & Coxão de Dentro & 6,29 \\
\hline Paleta & 10,79 & Vazio & 1,83 & Coxão de Fora & 2,94 \\
\hline Músculo & 4,16 & Recorte & 0,40 & Contra filé & 4,62 \\
\hline Osso & 3,63 & Osso & 0,60 & Filé mignon & 2,18 \\
\hline Sebo & 1,29 & Sebo & 1,92 & Patinho & 3,65 \\
\hline & & & & Tatu & 1,64 \\
\hline & & & & Maminha & 1,10 \\
\hline & & & & Picanha & 1,39 \\
\hline & & & & Chuleta & 6,01 \\
\hline & & & & Músculo & 2,86 \\
\hline & & & & Recorte & 2,03 \\
\hline & & & & Osso & 7,67 \\
\hline & & & & Sebo & 2,83 \\
\hline Total & 38,40 & & 13,90 & & 47,70 \\
\hline
\end{tabular}

Fonte: Viana \& Silveira (2007) 
o traseiro apresenta mais de um corte, buscou-se realizar a ponderação dos preços com relação a sua participação dentro do traseiro, para posteriormente obter um preço médio desta parte da carcaça a ponderar-se com o dianteiro e o costilhar, obtendo-se, assim, apenas uma série histórica indicativa do preço pago pelo consumidor.

\section{RESULTADOS}

Os preços reais pagos aos produtores de bovinos de corte no Rio Grande do Sul, conforme a figura 1, apresentou forte tendência de queda, sendo que o teste de hipótese do coeficiente angular da equação de regressão comprova a existência de comportamento declinante no período de 1977 a 1994. Destaca-se a década de 1980 com o período de maior intensidade no declínio dos preços. Os maiores preços encontrados na série histórica (Tabela 2) encontram-se nos anos de 1979 e 1980 com $\mathrm{R} \$ 6,56$ e R \$6,30 por quilograma de peso vivo, respectivamente.

Este comportamento de queda dos preços pagos ao produtor pode ser explicado pelo conhecido ganho de produtividade alcançado pela bovinocultura de corte nas últimas décadas, fruto do incremento tecnológico e das novas técnicas produtivas implementadas no setor que diminuíram a idade de abate e melhoraram os índices reprodutivos. Outro ponto importante que deve ser considerado é a expansão agrícola brasileira, principalmente quanto ao desenvolvimento da pecuária de corte no cerrado, que contribuiu para elevar o número efetivo de bovinos, segundo IBGE (2008), de 107 milhões de cabeças em 1977 para 205,8 milhões de cabeças em 2006. Esta elevação canalizou muitos investimentos, destacando-se a consolidação das maiores indústrias frigoríficas no centro do país, aumentando a oferta de carne brasileira para o

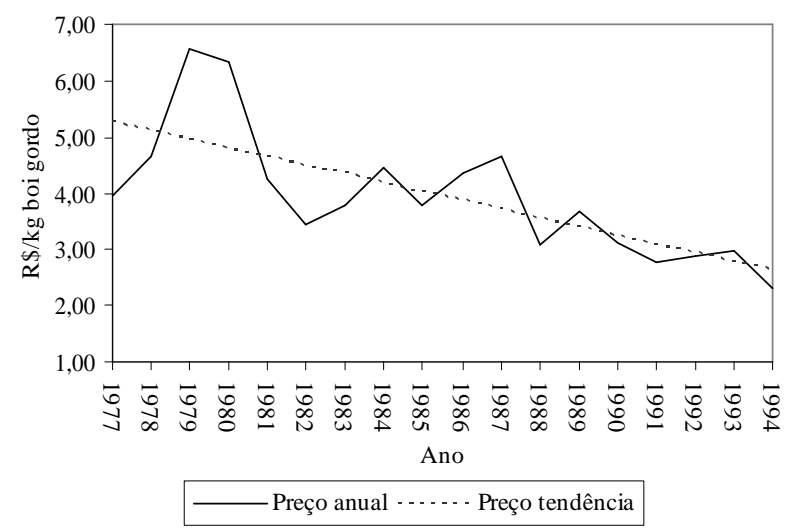

mercado interno e externo. Outro fato a ser considerado foi o aumento de oferta de outras carnes, principalmente de aves, com crescimento de produção, segundo Food Agricultural Organization-FAO (2008), de 698 mil toneladas em 1977 para 8,5 milhões de toneladas em 2006, e suínos, 834 mil toneladas em 1977 para 3,1 milhões de toneladas em 2006.

O período de 1995 a 2006 foi marcado pela estabilização monetária, abertura econômica, flutuação cambial e aumento do poder aquisitivo da população. Esse cenário econômico refletiu nos preços pagos aos produtores trazendo uma maior estabilidade dos preços, sem uma tendência significativa de queda. Nos dois últimos anos do período, foram encontrados os preços pagos mais baixos no Rio Grande do Sul da série histórica analisada (Tabela 2), respectivamente $\mathrm{R} \$ 1,67$ e $\mathrm{R} \$ 1,81$, por quilograma de peso vivo para os anos de 2005 e 2006.

Nesse contexto, avaliar o comportamento dos preços pagos pelo consumidor de carne bovina torna-se importante à medida que observa-se a tendência declinante dos preços pagos ao produtor. A Figura 2 representa a evolução dos índices de preços ao consumidor de diferentes cortes que representam o dianteiro, costilhar e traseiro da carcaça bovina, coletados pelo IEPE-UFRGS na região metropolitana de Porto Alegre, bem como os índices de preços pagos ao produtor, ambos com base 100 em 1977.

A partir desses índices, que determinam à evolução da variação dos preços a partir de uma base comum, podese observar que, no longo prazo, os preços não obtiveram o mesmo comportamento, apresentando deslocamentos principalmente a partir da década de 1980. Ou seja, os preços pagos pelo consumidor não acompanharam a mesma proporção de declínio dos preços pagos pelo quilograma de peso vivo do boi gordo no Rio Grande do Sul.

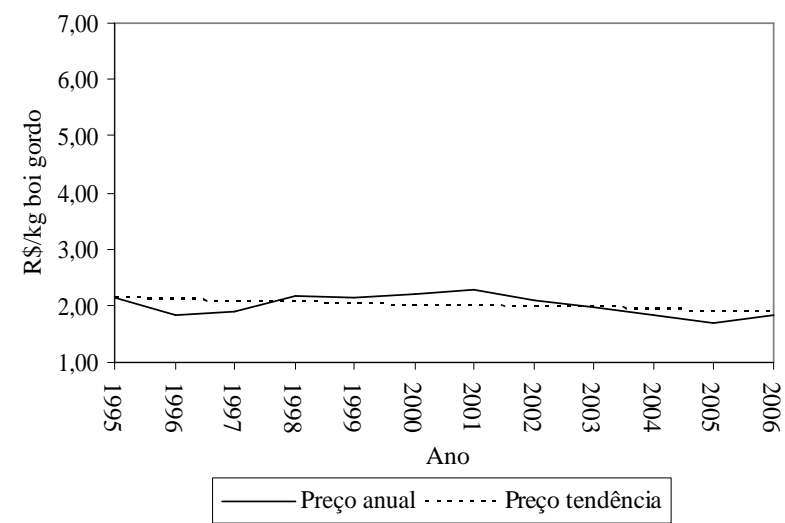

Figura 1 - Tendência e preços reais pagos aos produtores de bovinos de corte do Rio Grande do Sul por quilograma de peso vivo, nos períodos 1977-1994 e 1995-2006.

Fonte: Núcleo de Estudos e Pesquisas em Economia Agroindustrial-NEPEA (2007) 
Tabela 2 - Preços reais* pagos pelo consumidor de diferentes cortes de carne bovina, preços reais* pagos ao produtor por quilograma de peso vivo e seus respectivos índices de preço (IP**) no período de 1977 a 2006 no Rio Grande do Sul.

\begin{tabular}{|c|c|c|c|c|c|c|c|c|c|c|}
\hline \multirow{2}{*}{ Ano } & \multicolumn{2}{|c|}{ Filé } & \multicolumn{2}{|c|}{ Patinho } & \multicolumn{2}{|c|}{ Paleta } & \multicolumn{2}{|c|}{ Costela } & \multicolumn{2}{|c|}{ Preço ao produtor } \\
\hline & $\mathrm{R} \$ / \mathrm{kg}$ & IP & $\mathrm{R} \$ / \mathrm{kg}$ & IP & $\mathrm{R} \$ / \mathrm{kg}$ & IP & $\mathrm{R} \$ / \mathrm{kg}$ & IP & $\mathrm{R} \$ / \mathrm{kg}$ & IP \\
\hline 1977 & 16,34 & 100,00 & 15,28 & 100,00 & 7,71 & 100,00 & 7,71 & 100,00 & 3,94 & 100,00 \\
\hline 1978 & 18,30 & 112,00 & 16,93 & 110,83 & 8,88 & 115,11 & 9,64 & 125,00 & 4,67 & 118,52 \\
\hline 1979 & 24,49 & 149,86 & 22,39 & 146,58 & 12,59 & 163,19 & 13,98 & 181,31 & 6,56 & 166,25 \\
\hline 1980 & 24,54 & 150,16 & 22,42 & 146,74 & 13,26 & 171,90 & 13,49 & 174,95 & 6,30 & 159,72 \\
\hline 1981 & 20,24 & 123,89 & 18,63 & 121,94 & 11,06 & 143,47 & 11,09 & 143,81 & 4,24 & 107,52 \\
\hline 1982 & 17,69 & 108,24 & 16,40 & 107,36 & 9,50 & 123,22 & 9,91 & 128,53 & 3,45 & 87,53 \\
\hline 1983 & 19,38 & 118,61 & 18,17 & 118,93 & 10,65 & 138,11 & 10,77 & 139,60 & 3,82 & 96,86 \\
\hline 1984 & 20,29 & 124,20 & 19,15 & 125,37 & 11,34 & 146,99 & 11,35 & 147,19 & 4,47 & 113,27 \\
\hline 1985 & 17,94 & 109,77 & 16,71 & 109,37 & 9,26 & 120,09 & 9,68 & 125,57 & 3,82 & 96,86 \\
\hline 1986 & 17,41 & 106,53 & 16,17 & 105,83 & 9,37 & 121,54 & 10,49 & 136,02 & 4,35 & 110,28 \\
\hline 1987 & 21,53 & 131,78 & 18,26 & 119,52 & 9,15 & 118,66 & 9,27 & 120,17 & 4,62 & 117,22 \\
\hline 1988 & 15,25 & 93,31 & 12,83 & 83,97 & 7,40 & 95,94 & 7,93 & 102,77 & 3,11 & 78,91 \\
\hline 1989 & 14,32 & 87,62 & 11,98 & 78,39 & 7,35 & 95,25 & 7,18 & 93,15 & 3,40 & 86,28 \\
\hline 1990 & 16,43 & 100,52 & 13,75 & 90,01 & 7,97 & 103,33 & 7,83 & 101,49 & 3,12 & 79,15 \\
\hline 1991 & 13,84 & 84,73 & 11,84 & 77,48 & 6,94 & 89,94 & 6,98 & 90,54 & 2,79 & 70,68 \\
\hline 1992 & 14,36 & 87,90 & 12,26 & 80,26 & 6,90 & 89,45 & 7,03 & 91,15 & 2,88 & 73,07 \\
\hline 1993 & 14,04 & 85,93 & 11,71 & 76,66 & 6,83 & 88,50 & 6,87 & 89,03 & 2,98 & 75,54 \\
\hline 1994 & 13,54 & 82,87 & 11,54 & 75,55 & 6,20 & 80,45 & 6,46 & 83,76 & 2,32 & 58,92 \\
\hline 1995 & 12,46 & 76,26 & 11,51 & 75,35 & 5,79 & 75,12 & 5,59 & 72,50 & 2,11 & 53,59 \\
\hline 1996 & 11,17 & 68,38 & 9,87 & 64,62 & 5,19 & 67,27 & 5,03 & 65,22 & 1,83 & 46,45 \\
\hline 1997 & 12,11 & 74,10 & 9,60 & 62,85 & 5,26 & 68,17 & 5,79 & 75,05 & 1,90 & 48,19 \\
\hline 1998 & 18,01 & 110,25 & 10,07 & 65,94 & 6,15 & 79,73 & 7,23 & 93,73 & 2,16 & 54,90 \\
\hline 1999 & 21,32 & 130,50 & 10,03 & 65,65 & 6,14 & 79,57 & 7,01 & 90,95 & 2,14 & 54,23 \\
\hline 2000 & 22,66 & 138,65 & 10,15 & 66,43 & 6,00 & 77,80 & 6,91 & 89,55 & 2,20 & 55,74 \\
\hline 2001 & 20,81 & 127,36 & 10,27 & 67,24 & 6,08 & 78,82 & 7,21 & 93,44 & 2,27 & 57,61 \\
\hline 2002 & 19,69 & 120,49 & 10,22 & 66,93 & 5,85 & 75,82 & 6,27 & 81,32 & 2,11 & 53,40 \\
\hline 2003 & 17,40 & 106,51 & 9,24 & 60,48 & 5,63 & 73,01 & 5,63 & 72,97 & 1,97 & 49,86 \\
\hline 2004 & 16,84 & 103,07 & 8,95 & 58,61 & 5,45 & 70,69 & 5,51 & 71,47 & 1,82 & 46,09 \\
\hline 2005 & 15,96 & 97,68 & 8,63 & 56,50 & 4,90 & 63,52 & 5,51 & 71,45 & 1,67 & 42,45 \\
\hline 2006 & 16,08 & 98,42 & 8,73 & 57,14 & 4,87 & 63,11 & 5,67 & 73,52 & 1,81 & 45,93 \\
\hline
\end{tabular}

* Deflacionados para dezembro de 2006.

** IP (base $100=1977)$.

Fonte: NEPEA (2007)

Porém, os distintos cortes apresentam diferença de deslocamentos com relação ao índice de preço ao produtor. O Plano Real instituído na década de 1990 trouxe a estabilidade econômica e o aumento do poder aquisitivo da população. Esse aumento de renda contribuiu para o menor declínio dos preços ao consumidor. Apesar disso, os preços continuaram levemente declinantes, havendo comportamento similar para os cortes de alcatra, coxão de dentro, coxão de fora, chuleta, patinho e paleta, estes, cortes de maior comercialização no mercado interno. Entretanto, dois cortes apresentaram comportamentos distintos dos demais: a costela e o filé mignon. A costela apresentou elevação de preços a partir de 1995, não acompanhando a queda do índice de preço ao produtor. Pode-se explicar esta tendência pelo fato de que a costela é um corte de carne bovina de preparo em churrascos, costume tradicional da população gaúcha. 
Tabela 3 - Preços reais* pagos pelo consumidor por diferentes cortes da carcaça bovina e seus respectivos índices de preços (IP**) no período de 1977 a 2006 no Rio Grande do Sul.

\begin{tabular}{|c|c|c|c|c|c|c|c|c|}
\hline \multirow{2}{*}{ Ano } & \multicolumn{2}{|c|}{ Alcatra } & \multicolumn{2}{|c|}{ Chuleta } & \multicolumn{2}{|c|}{ Coxão de dentro } & \multicolumn{2}{|c|}{ Coxão de fora } \\
\hline & $\mathrm{R} \$ / \mathrm{kg}$ & IP & $\mathrm{R} \$ / \mathrm{kg}$ & IP & $\mathrm{R} \$ / \mathrm{kg}$ & IP & $\mathrm{R} \$ / \mathrm{kg}$ & IP \\
\hline 1977 & 16,34 & 100,00 & 11,49 & 100,00 & 15,09 & 100,00 & 15,09 & 100,00 \\
\hline 1978 & 18,50 & 113,19 & 13,19 & 114,82 & 16,95 & 112,33 & 16,95 & 112,33 \\
\hline 1979 & 24,49 & 149,86 & 18,10 & 157,55 & 22,61 & 149,83 & 22,61 & 149,83 \\
\hline 1980 & 24,53 & 150,11 & 18,02 & 156,85 & 23,25 & 154,06 & 23,25 & 154,06 \\
\hline 1981 & 20,25 & 123,95 & 14,79 & 128,76 & 18,98 & 125,77 & 18,98 & 125,77 \\
\hline 1982 & 17,67 & 108,16 & 12,87 & 112,01 & 16,52 & 109,49 & 16,52 & 109,49 \\
\hline 1983 & 19,36 & 118,49 & 14,17 & 123,33 & 18,25 & 120,98 & 18,25 & 120,98 \\
\hline 1984 & 20,29 & 124,17 & 14,96 & 130,18 & 19,06 & 126,28 & 19,06 & 126,28 \\
\hline 1985 & 17,96 & 109,90 & 13,21 & 115,00 & 16,69 & 110,62 & 16,69 & 110,62 \\
\hline 1986 & 17,42 & 106,59 & 12,83 & 111,64 & 16,55 & 109,67 & 16,55 & 109,67 \\
\hline 1987 & 21,57 & 131,98 & 15,30 & 133,15 & 19,36 & 128,29 & 19,36 & 128,29 \\
\hline 1988 & 15,25 & 93,36 & 10,53 & 91,68 & 13,56 & 89,85 & 13,56 & 89,85 \\
\hline 1989 & 14,11 & 86,35 & 10,01 & 87,16 & 12,66 & 83,90 & 12,66 & 83,90 \\
\hline 1990 & 16,43 & 100,55 & 11,09 & 96,54 & 14,65 & 97,06 & 14,65 & 97,06 \\
\hline 1991 & 13,99 & 85,60 & 10,10 & 87,88 & 12,28 & 81,40 & 12,28 & 81,40 \\
\hline 1992 & 14,39 & 88,09 & 9,86 & 85,80 & 12,76 & 84,54 & 12,76 & 84,54 \\
\hline 1993 & 14,00 & 85,68 & 9,79 & 85,20 & 12,32 & 81,67 & 12,32 & 81,67 \\
\hline 1994 & 13,62 & 83,33 & 9,59 & 83,47 & 12,28 & 81,37 & 12,28 & 81,37 \\
\hline 1995 & 12,36 & 75,62 & 9,73 & 84,68 & 12,25 & 81,20 & 12,25 & 81,20 \\
\hline 1996 & 10,95 & 67,04 & 8,34 & 72,62 & 10,51 & 69,62 & 10,51 & 69,62 \\
\hline 1997 & 11,20 & 68,52 & 8,55 & 74,39 & 10,29 & 68,16 & 10,29 & 68,16 \\
\hline 1998 & 12,85 & 78,65 & 9,56 & 83,17 & 10,77 & 71,39 & 10,77 & 71,39 \\
\hline 1999 & 13,62 & 77,24 & 9,52 & 82,85 & 10,88 & 72,10 & 10,88 & 72,10 \\
\hline 2000 & 12,82 & 78,48 & 9,32 & 81,10 & 10,97 & 72,73 & 10,97 & 72,73 \\
\hline 2001 & 12,71 & 77,79 & 9,14 & 79,52 & 11,05 & 73,22 & 11,05 & 73,22 \\
\hline 2002 & 12,33 & 75,48 & 8,86 & 77,11 & 10,95 & 72,58 & 10,95 & 72,58 \\
\hline 2003 & 11,10 & 67,95 & 8,05 & 70,10 & 10,00 & 66,27 & 10,00 & 66,27 \\
\hline 2004 & 10,75 & 65,81 & 7,70 & 67,01 & 9,55 & 63,30 & 9,55 & 63,30 \\
\hline 2005 & 10,63 & 65,05 & 7,47 & 65,06 & 9,44 & 62,55 & 9,44 & 62,55 \\
\hline 2006 & 11,10 & 67,96 & 7,50 & 65,30 & 9,49 & 62,89 & 9,49 & 62,89 \\
\hline
\end{tabular}

* Deflacionados para dezembro de 2006.

** IP (base $100=1977)$.

Fonte: NEPEA (2007)

$\mathrm{O}$ aumento de renda trouxe uma maior procura por este tipo de carne, corte este que não apresenta produto substituto no mercado, ao contrário dos outros cortes bovinos que podem ser substituídos por carne de frango ou suíno. Esse fato pode ser a explicação da elevação do preço da costela, a partir de 1996, no mercado gaúcho, voltando a obter queda de preço apenas no ano de 2001. 

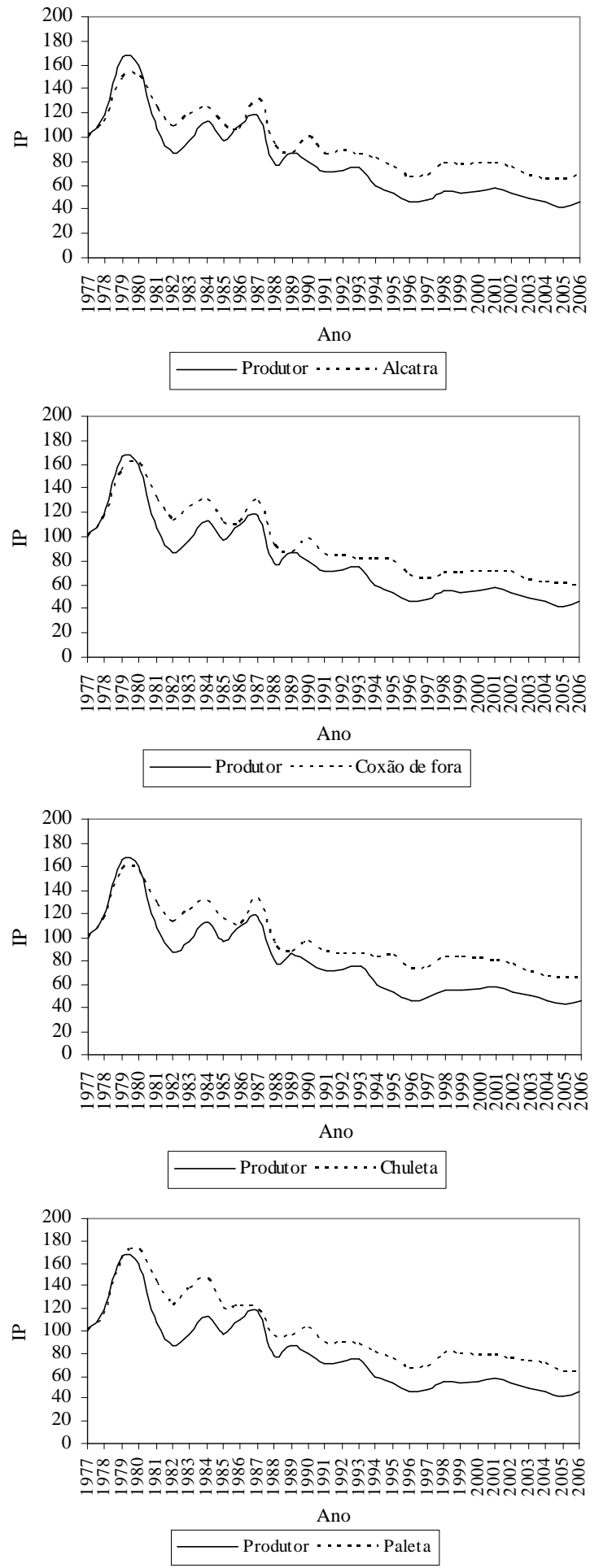

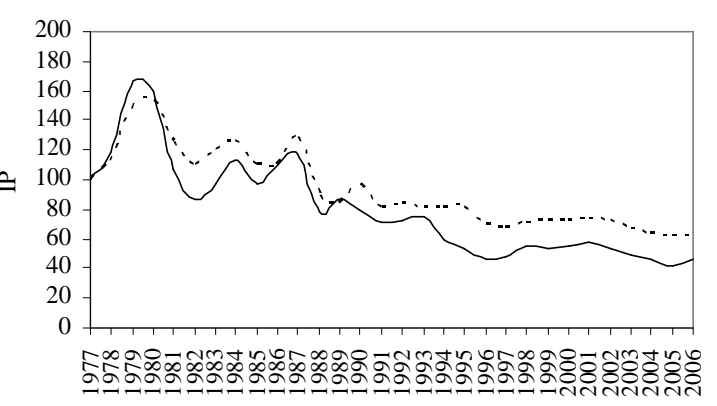

Ano
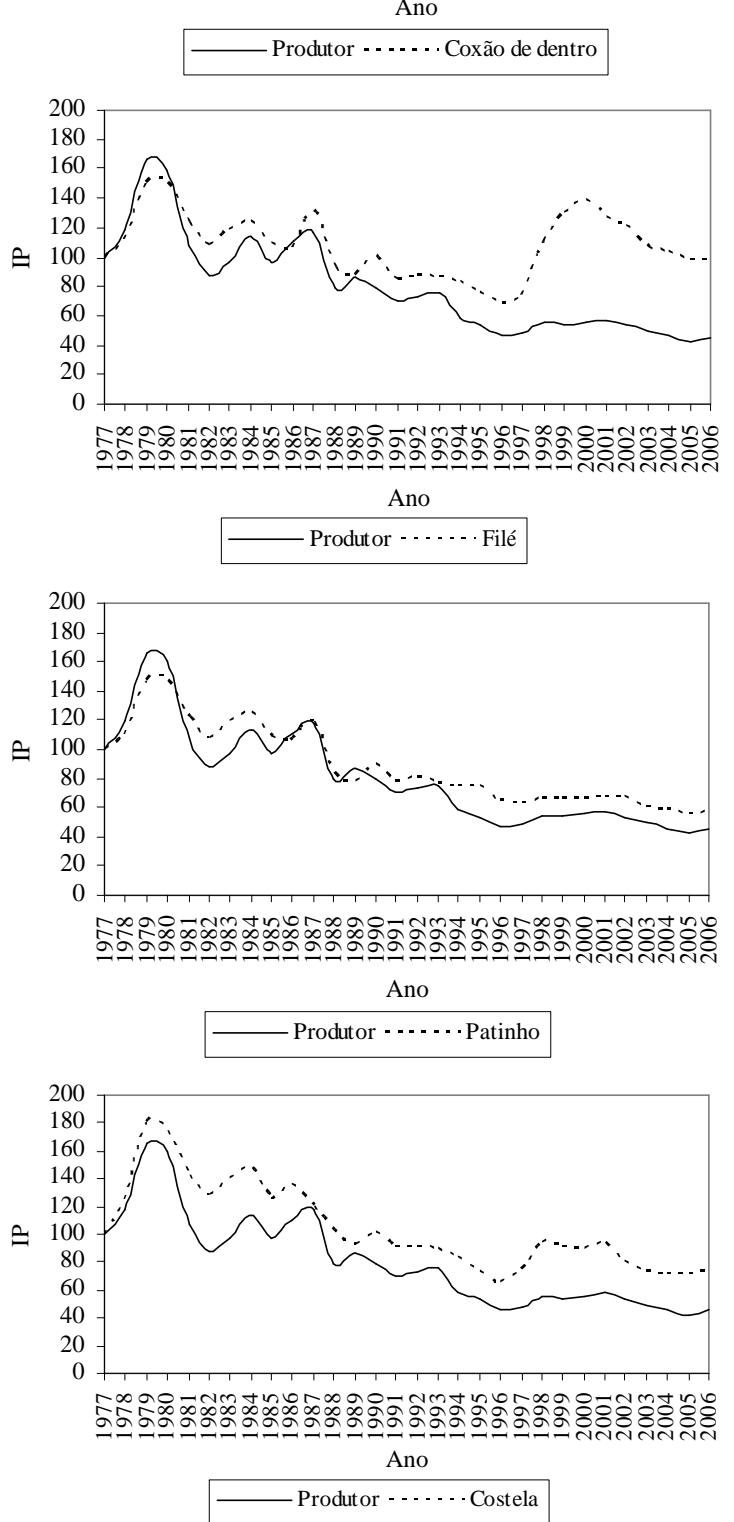

Figura 2 - Índices de preços (IP) dos preços pagos ao produtor de bovinos de corte e dos preços pagos pelo consumidor pelo diferentes cortes de carne bovina no Rio Grande do Sul de 1977 a 2006.

Fonte: NEPEA (2007) 
O filé mignon apresentou comportamento atípico em relação aos outros cortes analisados, obtendo grande elevação de preço no ano de 1996, mantendo até o ano de 2006 diferenças com relação à curva de índice do preço ao produtor.

Durante a década de 1990, foi lançada uma série de incentivos para a modernização das plantas frigoríficas com o intuito de adequar os estabelecimentos às normas dos possíveis países importadores de carne brasileira e diminuir a ociosidade do setor. Miranda \& Motta (2001) destacam o crescimento das exportações de carne brasileira a partir do ano de 1996, ressaltando o crescimento das exportações de cortes especiais, como filé mignon, alcatra e contra-filé para distribuidores especializados da União Européia.

Em razão da desvalorização cambial ocorrida no final da década de 1990, a exportação de filé mignon se tornou mais rentável para os frigoríficos do Estado, o que resultou no aumento de preço do produto no mercado interno. A maior rentabilidade com esse corte pela indústria não foi capaz de elevar o preço pago ao produtor, tendo em vista a pequena participação do filé mignon na carcaça total. Assim, o índice de preço do filé mignon, apresentado na Tabela 2, demonstrou comportamento distinto do índice de preço ao produtor, apesar do índice apresentar queda a partir do ano de 2001.

Na Figura 3, representa-se o índice de preço agregado dos cortes, simulando o índice da carcaça total, comparando-se com o índice do preço pago ao produtor de bovinos de corte no Rio Grande do Sul. Cabe ressaltar que essa série histórica de preços pagos ao consumidor (Figura 3) representa apenas uma simulação dos preços médios pagos pelo consumidor.

Observa-se que as curvas não apresentam o mesmo comportamento, sendo que os preços pagos ao produtor desvalorizaram-se em maior grau do que os preços pagos pelos consumidores. Apesar do deslocamento da curva, as tendências de quedas e elevações apresentam similaridade. Os maiores preços pagos aos produtores e pagos pelos consumidores foram encontrados (Tabela $2 \mathrm{e}$ 3) nos anos de 1979 e 1980, e os menores preços nos últimos anos do período analisado, com exceção para os cortes filé mignon e costela, como já foi destacado anteriormente. Os dados induzem a idéia de que o setor a jusante da cadeia bovina do Rio Grande do Sul tem se apropriado, ao longo das últimas décadas, da maior parte do valor pago pelos consumidores.

O setor de hiper/supermercados tende a agregar valor ao produto carne, visto que, em grande parte, recebe as carcaças inteiras e subdividi-a em diferentes cortes,

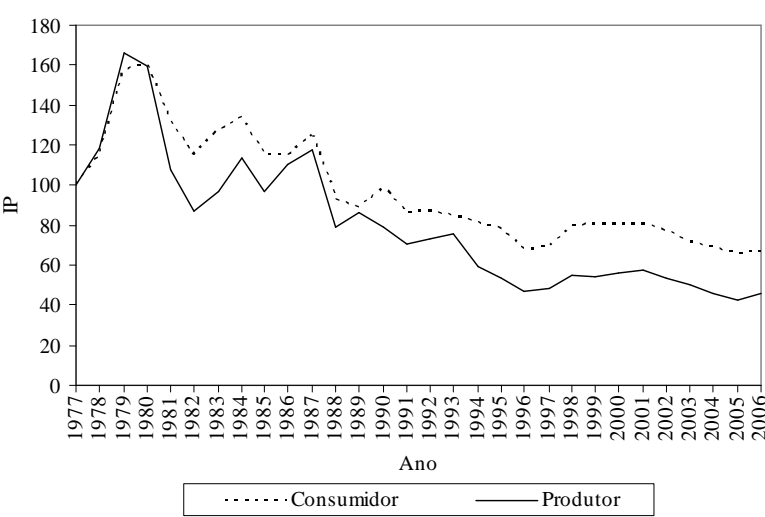

Figura 3 - Índices de preços (IP) dos preços pagos ao produtor de bovinos de corte e dos preços pagos pelo consumidor de carne bovina no Rio Grande do Sul de 1977 a 2006.

Fonte: NEPEA (2007)

possibilitando produtos para consumo de todas as faixas de renda. $\mathrm{O}$ varejo, como elo da cadeia mais próximo do consumidor, consegue regular os preços conforme a demanda, controlando, de certa forma, os preços exercidos em toda a cadeia.

\section{CONCLUSÕES}

Os preços pagos por quilograma de peso vivo do boi gordo no Rio Grande do Sul apresentaram tendência declinante significativa de 1977 a 1994. Porém, os preços obtiveram maior estabilidade de 1995 a 2006, sem tendência significativa de queda no período, fruto da estabilidade econômica e aumento do poder aquisitivo da população. Os preços pagos pelo consumidor não apresentaram o mesmo comportamento de queda dos preços pagos ao produtor, obtendo menor desvalorização no período analisado. Ou seja, o setor a jusante da cadeia, nas últimas décadas, tendeu a apropriar-se da maior parte do valor pago pelos consumidores.

Dentre os cortes analisados, a alcatra, coxão de fora, coxão de dentro, chuleta, patinho e paleta apresentaram comportamento semelhante de decréscimo de preços no período de 1977 a 2006. Os cortes filé mignon e costela apresentaram comportamento distinto dos demais, obtendo elevação de preço, principalmente, no período pós 1996, comportamento este influenciado, no caso do filé mignon, pelo crescimento das exportações de cortes especiais, e no caso da costela, pelo aumento do poder aquisitivo e do consumo de carnes de churrasco, além do corte não apresentar produto substituto para comercialização. 


\section{REFERÊNCIAS BIBLIOGRÁFICAS}

CENTRO DE ESTUDOS E PESQUISAS ECONÔMICAS. Banco de dados 2007. Disponível em: <http:// [www.ufrgs.br/iepebanco'>. Acesso em: 14 mar. 2007.

\section{EMPRESA DE ASSISTÊNCIA TÉCNICA E EXTENSÃO} RURAL DO RIO GRANDE DO SUL. Associação Riograndense de Empreendimentos de Assistência Técnica e Extensão Rural. Dados Econômicos. 2007. Disponível em: <hittps:///extranet.emater.tche.bril login.php>. Acesso em: 3 mar. 2007.

FINAMORE, E.B.M.C.; GOMES, A.P. Uma alternativa à análise de tendência em séries temporais. In: CONGRESSO BRASILEIRO DE ECONOMIA E SOCIOLOGIA RURAL, 37., 1999, Foz do Iguaçu. Anais... Brasília, DF: SOBER, 1999. p.1-9.

FOOD AGRICULTURAL ORGANIZATION. Estatísticas FAO. 2008. Disponível em: $\langle\bar{h}$ ttp ://faostat.fao.org $\rangle$. Acesso em: 10 jun. 2008.

FUNDAÇÃO GETÚLIO VARGAS. IGP-DI índice geral

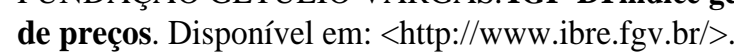
Acesso em: 13 jan. 2007.

GASQUES, J.G. et al. Desempenho e crescimento do agronegócio no Brasil. Brasília, DF: IPEA, 2004. (Texto para discussão, 1009). Disponível em: <http:// iwww.ipea.gov.br >. Acesso em: 18 mar. 2005.

\section{INSTITUTO BRASILEIRO DE GEOGRAFIA E}

ESTATÍSTICA. Dados estatísticos. Rio de Janeiro, 2008.

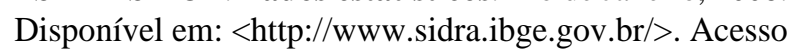
em: 10 jun. 2008.

JOHNSTON, J. Métodos econométricos. São Paulo: Atlas, 1977. 313p.
KAZMIER, L.J. Estatística aplicada à economia e administração. São Paulo: McGraw-Hill, 1982. 376p.

MIRANDA, S.H.G.; MOTTA, M.A.S.B. Exportação de carne bovina brasileira: evolução por tipo e destino. In: CONGRESSO BRASILEIRO DE ECONOMIA E SOCIOLOGIA RURAL, 39., 2001, Recife. Anais... Brasília, DF: SOBER, 2001. CD-ROM

MONTOYA, M.A.; PARRÉ, J.L. O agronegócio brasileiro no final do século XX: estrutura produtiva, arquitetura organizacional e tendências. Passo Fundo: UPF, 2000. 2v.

\section{NÚCLEO DE ESTUDOS E PESQUISAS EM} ECONOMIAAGROINDUSTRIAL. Departamento de educação agrícola e extensão rural. Dados primários elaborados pelo núcleo. Santa Maria: UFSM, 2007. Disponível em: <www.ufsm.br/nepea mar. 2007.

RIO GRANDE DO SUL. Assembléia Legislativa. CPI das carnes relatório final. Porto Alegre, 2003. 764p.

Disponível em: <http://wwwal.rs.gov.bry. Acesso em: 15 jun. 2004.

TELLECHEA, F. Análise dos custos de transação no setor industrial da cadeia produtiva de carne bovina no Rio Grande do Sul. 2001. 98p. Dissertação (Mestrado em Economia Rural)-Universidade Federal do Rio Grande do Sul, Porto Alegre, 2001.

VIANA, J.G.A.; SILVEIRA, V.C.P. A relação entre o preço pago pelo consumidor de carne bovina em Santa Maria e o recebido pelo produtor de gado de corte no Rio Grande do Sul, Brasil. Ciência Rural, Santa Maria, v.37, n.4, p.1122-1127, 2007. 